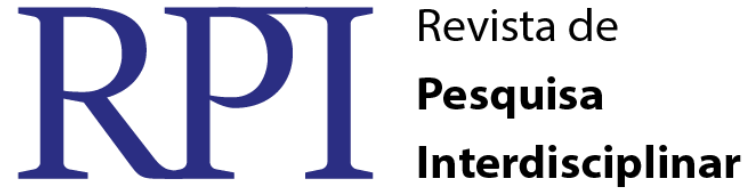

\section{RELATO DE EXPERIÊNCIA: TRABALHANDO PROJETOS DE ENSINO EM ESTÁGIO SUPERVISIONADO}

\author{
YAM DE SOUSA SANTOS 1
}

${ }^{1}$ Graduando em Licenciatura em Ciências Biológicas pelo Centro de Formação de Professores da Universidade Federal de Campina Grande - CFP/UFCG.

e-mail: yamssantos@gmail.com

\section{RESUMO}

O Estágio Supervisionado faz parte do Projeto Pedagógico dos Cursos (PPC) de Licenciatura. É uma das partes mais importantes para os cursos de graduação. Através do período de observação e regência, podemos aproxima-se da realidade histórica, econômica e social da comunidade escolar. É o período em que se une a teoria aprendida ao longo do curso com a prática na forma de regência. Compreendendo a importância do Estágio Supervisionado na formação docente este trabalho tem como objetivo relatar a experiência de trabalhar com projetos de ensino. As atividades foram realizadas em uma escola pública de ensino médio, situada na cidade de Cajazeiras, alto sertão da Paraíba. A atuação com projetos de ensino vai contra o modelo tradicional de ensino, permite a atuação do aluno como sujeito ativo do processo de aprendizagem e torna-se possível trabalhar com múltiplas inteligências. O projeto de ensino intitulado "Sistema Respiratório: anatomia, fisiologia e a influência do meio ambiente externo" possuiu como público-alvo, alunos do $3^{\circ}$ ano do ensino médio e foi baseado em dois livros didáticos. Devido à flexibilidade de um planejamento, o projeto sofreu alterações durante a sua execução, de forma que os conteúdos e atividades fossem reorganizadas. Sendo assim, o conteúdo foi trabalhado de forma a utilizar três modalidades ensino: utilizando infográficos; atividade experimental e simulação. Desta forma, fica evidente a importância de um bom planejamento sempre visando imprevistos. Foi perceptível, também, uma maior interação dos alunos quando se trabalha com metodologias diferenciadas que vão além do livro didático.

Palavras Chaves: Pedagogia de projetos; ensino tradicional; aprendizagem significativa.

\section{EXPERIENCE REPORT: ACTING WITH TEACHING PROJECT IN SUPERVISED INTERNSHIP}

\begin{abstract}
The supervised internship it's a part of pedagogical project of course (PPC) of graduation and is the most important part of them. Through the period of observation and regency we can come near to history, economy and social reality of the school community. It's the period that the theory learned during the course makes synergy with the practice in regency on the classroom. With the
\end{abstract}


comprehension of the importance of supervised internship, this article have the objective to relate an experience to acting with teaching projects. The project was realized on a public secondary school located on Cajazeiras city, on Paraíba. Work with teaching projects is characterized like a methodology that contradicts the traditional education. Makes possible the actuation of the student as a active subject on the learning process and makes possible work with multiple intelligences on the classroom. The teaching project entitled "Respiratory System: anatomy, physiology and influence of external environment" have owned students of 3rd year of secondary school as target audience and was based on two didactic books. The flexibility of a planning became possible do modifications on the contents and activities during the execution of the project. So the content was explained using three teaching methods: info-graphics; experimental activity and simulation. So is evident that a good planning, created aiming unexpected cases, it's important to make a good regency. Was noticeable too a better interaction of students when is acting with methodologies that go beyond didactic books.

Keywords: Teaching projects; traditional education; significant learning.

\section{INTRODUÇÃO}

O Estágio Supervisionado é uma das disciplinas mais importantes para os cursos de graduação, principalmente nas licenciaturas. É nele que, através do período de observação e regência, podemos torna-se mais próximos da realidade histórica, econômica e social da comunidade escolar. Legalmente, deve fazer parte do Projeto Pedagógico dos Cursos (PPC) de licenciaturas, contando com 400 horas de prática como componente curricular supervisionado (PIMENTA \& LIMA, 2012).

Compreendendo a importância do Estágio Supervisionado na formação docente, este trabalho visa realizar uma descrição detalhada sobre as atividades realizadas durante o Estágio Supervisionado IV do Curso de Licenciatura em Ciências Biológicas. A disciplina supracitada caracteriza-se, principalmente, na inserção do aluno na prática docente e na execução de projetos de ensino. Parte destas atividades foram realizadas na Instituição Concedente, uma escola pública e estadual, situada na Cidade de Cajazeiras - alto sertão do Estado da Paraíba.

\section{DESENVOLVIMENTO}

\subsection{A complexidade no espaço escolar: as múltiplas inteligências e a perspectiva de aprendizagem significativa}

Grande parte das escolas continua adotando o modelo de aprendizagem mecânica, sem significado, memorística e acumulativa, onde o aluno é visto como um sujeito passivo durante o processo de ensino e aprendizagem (BIZZO, 2012; NOGUEIRA, 2001; MOREIRA, 2011).

Paulo Freire (1987) chama de educação bancária o processo onde o aluno teria uma "mente vazia" e o professor teria a função de "enchê-la" com os conteúdos escolares. Este modelo de ensino

RPI Revista de Pesquisa Interdisciplinar, Cajazeiras, v. 1, Ed. Especial, 437 - 443, set/dez. de 2016. 
faz com que o professor atue como se a sala de aula fosse homogênea, considerando que todos os alunos aprendem da mesma forma. Um dos grandes problemas no Ensino da Biologia, acentuados a esse modelo de ensino, é a forma como os conteúdos são trabalhados, uma vez que demandam memorização. Exemplo claro da ineficácia desse processo é quando tentamos retomar determinadas minúcias e estas foram esquecidas, nos dando a incerteza de que algo fora, de fato, "depositado" (BIZZO, 2012; FEITOSA, 2010; LEÃO, 1999)

Para superarmos estas dificuldades e desafios, é preciso ter em mente que o aluno é o principal sujeito da aprendizagem, mas não aquele que apenas recebe a ação. É preciso ter consciência que o aluno é um componente complexo na produção do conhecimento e que a aprendizagem é resultado de ações de um sujeito. Quando a concepção de ensino é centrada no aluno, é possível reconhecer a existência de um espectro de competências e múltiplas inteligências. Esta concepção de ensino, por sua vez, contraria o conceito de ensino massificado e mecanicista já que considera particularidades de cada sujeito. Desta forma, o aluno é o responsável final por sua aprendizagem (COLL, 1994; FEITOSA, 2010; NOGUEIRA, 2001; MOREIRA, 2011).

Segundo Coll (1994), antes de entrar em sala de aula, o discente possui conhecimentos prévios (concepções alternativas) sobre determinados assuntos. Estes conhecimentos prévios associados ao conteúdo ministrado pelo professor se unem construindo um conceito. Este processo de assimilação é chamado de aprendizagem significativa (MOREIRA, 2011).

Uma alternativa que possibilita mudanças e permite o desenvolvimento destas múltiplas inteligências é planejar as atividades em projetos de ensino. Uma vez que estes permitem a articulação entre disciplinas e buscam analisar os problemas sociais e existenciais, contribuindo para a sua solução por meio da prática concreta dos alunos e da comunidade, além de possibilitar a apropriação do conhecimento científico (FEITOSA, 2010; NOGUEIRA, 2001).

\subsection{O projeto de Ensino como organização de atividades em Unidades Didáticas de Biologia}

O planejamento das atividades de regência foi elaborado a partir do roteiro para elaboração de Projeto de Ensino (PE) disponibilizado pela docente responsável pela disciplina. O assunto abordado no PE foi escolhido em coparticipação com a docente responsável pela disciplina na Instituição Concedente. Desta forma, o planejamento foi pensado para ser realizado em cinco aulas e as estratégias de intervenção foram elaboradas a partir dos conteúdos inclusos no livro didático adotado pela escola.

Buscou-se trabalhar com PE uma vez compreendida a sua importância como ferramenta para incentivar o repensar e o refazer do ensino na disciplina Biologia, sendo assim norteado por concepções relacionadas à educação, ao conhecimento, à aprendizagem, ao ensino e ao currículo (GODEFROID, 2010). Desta forma, adotou-se três atividades em sua elaboração: (I) experimento para

RPI Revista de Pesquisa Interdisciplinar, Cajazeiras, v. 1, Ed. Especial, 437 - 443, set/dez. de 2016. 
avaliar a qualidade do ar; (II) aula prática sobre o sistema respiratório; (III) oficina sobre a ventilação pulmonar. Tanto o experimento, como a oficina foram atividades propostas pelos livros didáticos.

O PE intitulado 'Sistema Respiratório: anatomia, fisiologia e a influência do meio ambiente externo' possuía como público-alvo, alunos do $3^{\circ}$ ano do ensino médio, sendo os autores adotados: Mendonça (2013) e Shimabukuro (2010). Tendo como principal objetivo explorar a complexidade anatômica e fisiológica do sistema respiratório humano, bem como diferenciá-lo dos demais sistemas análogos existentes em outros grupos de animais a partir de aulas expositivas e dialogadas com o auxílio das atividades anteriormente citadas.

Os conteúdos seguiram uma ordem sistematizada, distribuindo-se em 05 aulas que abordavam os seguintes temas: (1) a saúde humana e o desenvolvimento industrial; (2) O sistema respiratório no Reino Animalia e (3) O Sistema Respiratório. A avaliação seria, em grande parte do tempo, contínua e baseada na observação durante sala de aula (interações aluno-aluno e professor-aluno; participação do discente nas atividades propostas).

\subsection{Intervenção no espaço escolar - Regência Colaborativa}

Todo o planejamento das atividades de regência foi elaborado tendo como percussor o Projeto de Ensino. No entanto, surgiu a proposta, feita pela professora supervisora, de "inverter" a ordem dos conteúdos e reorganizá-los. Neste caso, não houve uma mudança radical no projeto de ensino, apenas uma reorganização de exposição de conteúdos, graças ao caráter flexível do planejamento. Segundo Turra (1986), o planejamento envolve a precisão de resultados desejáveis e grande parte da eficácia do plano de ensino depende da organização, coerência e flexibilidade deste.

Embora o capítulo do Livro Didático (LD) adotado pela escola abordasse apenas a Anatomia e Fisiologia do Sistema Respiratório da espécie humana, viu-se a necessidade de se trabalhar com este sistema de forma comparada, por isto a utilização de 2 LD para o projeto. Para tornar o assunto mais didático e contribuir para o entendimento dos alunos foram preparados recursos audiovisuais para todas as aulas.

Para a primeira aula estava previsto a execução da aula abordando o tema "A saúde humana e o desenvolvimento industrial", porém ao invés disso o tema explorado foi "O Sistema Respiratório Humano". Durante esta foram utilizadas apresentações em slides que possuíam imagens e desenhos esquemáticos relacionados à anatomia do sistema, bem como animações e infográficos que auxiliaram na compreensão dos processos respiratórios como a ventilação pulmonar, por exemplo.

Durante o percurso da aula, foram levantadas as questões evolutivas e as possíveis pressões ambientais sofridas por nossos ancestrais para que pudéssemos ter as atuais estruturas, entre outras. Não foi possível realizar a aula prática, anteriormente planejada devido à falta de equipamentos no laboratório. Ao invés disso, foi executado a parte inicial do experimento "avaliando a qualidade do ar" RPI Revista de Pesquisa Interdisciplinar, Cajazeiras, v. 1, Ed. Especial, 437 - 443, set/dez. de 2016. 
(figura 1. a. b.). Onde foram colocados 2 materiais em locais aleatórias da escola, escolhido pelos próprios discentes. Este tipo de atividade se caracteriza como um importante instrumento alternativo que se distanciam do ensino tradicional. Tende, também a melhorar a aprendizagem e intensifica o papel do discente na atividade (SUART E MARCONDES, 2009).

A partir do segundo dia, as aulas foram executadas sem o recurso dos slides, devido à inviabilização do equipamento na instituição concedente. Sendo assim, os principais recursos utilizados nas aulas seguintes foram o quadro branco e pinceis de quadro.

Durante a segunda e terceira aula foi ministrado o conteúdo "O Sistema Respiratório no Reino Animalia", onde foram abordados de forma comparada os diferentes meios de respiração entre os animais, focando principalmente em seus aspectos evolutivos. Este conteúdo estava previsto para ser discutido em apenas uma aula, no entanto, no primeiro dia de estágio poucos alunos compareceram, devido a problemas de transporte para alunos oriundos de regiões vizinhas. Fez-se, então, necessário abordar novamente a respiração humana, sendo realizado um replanejamento para este dia. Devido à curta duração das aulas, ao invés da oficina utilizou-se do material (figura 1. c. d. e. f.) já preparado para realizar uma simulação dos movimentos respiratórios durante a explicação do conteúdo, caracterizando-se como uma estratégia rápida de adaptação à situação encontrada naquele momento.

Foi notável que a participação dos alunos tornou-se mais efetiva quando a aula não estava "presa" aos slides. Observou-se também que a aula com os slides se tornava mais rápida, menos interativa e muitas vezes se limitava ao que estava exposto na figura. Com o quadro, era possível retornar a outras partes, desenhar, apagar e redesenhar estruturas que fossem importantes.

No último dia seriam coletados os materiais da experimentação para que fossem examinados em sala de aula. No entanto, os materiais colocados na instituição concedente foram removidos por motivos e autores desconhecidos. Embora o imprevisto, o experimento ainda pode ser examinado, pois já pensando neste tipo de problemas, foram colocados materiais em locais de difícil acesso em outros pontos da cidade. Durante a análise foram realizadas perguntas que procurassem incentivar a curiosidade do aluno, bem como sua capacidade investigativa. A partir do experimento e dos questionamentos provindos deste, foi possível relacionar com o conteúdo trabalhado nas aulas anteriores, quando os alunos eram questionados sobre quais atitudes do nosso dia a dia poderiam causar problemas nas estruturas respiratórias.

As atividades desenvolvidas durante o estágio corresponderam às expectativas, pois a turma exerceu uma participação bastante ativa. As mudanças ocorridas no planejamento se fizeram necessárias e tornaram possível apresentar o conteúdo com clareza e maior segurança. Segundo Turra (1986) mudanças deste tipo são completamente normais, visto que não existe um planejamento imutável, definitivo.

RPI Revista de Pesquisa Interdisciplinar, Cajazeiras, v. 1, Ed. Especial, 437 - 443, set/dez. de 2016. 
Evidentemente, a atividade de experimentação investigativa incentivou a maior participação dos alunos, pois este tipo de abordagem é focado em colocar o aluno diante de uma situação-problema, direcionando-o para sua resolução. Desta forma, os alunos puderam discutir, questionar suas hipóteses e ideias iniciais à luz do quadro teórico, coletar e analisar os dados para encontrar possíveis soluções para o problema. Sendo assim, este tipo de atividade contribui para o raciocínio lógico do aluno sobre a situação ao mesmo tempo em que é possível criar e apresentar argumentos na tentativa de analisar os dados e gerar uma conclusão plausível (SUART E MARCONDES, 2009).

\section{CONCLUSÃO}

O Estágio Supervisionado IV nada mais é que um estágio de amadurecimento. Talvez seja a fase mais difícil do curso, embora seja a mais prazerosa. Após ter acumulado toda a carga teórica oferecida pelo curso e ter finalizado outros três estágios obrigatórios, é neste onde são reconsideradas todas as falhas e sucessos durante as intervenções realizadas nas instituições concedentes. Esta etapa de reflexão é um dos atos mais importantes, pois é a partir daí que se inicia o processo de criação de um projeto de ensino que possa garantir uma aprendizagem significativa.

A produção dos materiais previamente caracterizou-se como um importante fator contribuinte para o planejamento da regência, pois somente devido a este que foi possível realizar algumas atividades propostas.

Trabalhar com este tipo de planejamento mostrou-se como uma grande oportunidade de ir além do livro didático. Permitiu uma maior interação com a sala de aula e garantiu a atuação do aluno na sala de aula. Tornando-se bastante evidente a importância de um bom planejamento sempre visando imprevistos.

\section{AGRADECIMENTOS}

À professora Antonia Arisdélia Fonseca Matias Aguiar Feitosa que orientou esta importante etapa da graduação e me permitiu ter uma compreensão de mundo de forma mais ampla e humanizada. E ao Programa Institucional de Bolsas de Iniciação à Docência (PIBID) que, através deste auxílio, permitiu que os materiais utilizados durante a regência pudessem ser comprados.

\section{REFERÊNCIAS BIBLIOGRÁFICAS}

BIZZO, Nelio. Metodologia do ensino de Biologia e estágio supervisionado. São Paulo: Ática, 2012.

COLL, C. Aprendizagem escolar e construção do conhecimento. Porto Alegre: Artmed, 1995.

FEITOSA, Antônia Arisdelia Fonseca Matias Aguiar. Planejando o Estágio em forma de projetos; Projetos e Atores em Educação; Proposição Curricular na Modalidade de Projetos. In: Ciências Naturais / Maria de Lourdes Pereira (Organizadora) - João Pessoa: Editora Universitária/UFPB. V.4. p. $283-298.2010$

RPI Revista de Pesquisa Interdisciplinar, Cajazeiras, v. 1, Ed. Especial, 437 - 443, set/dez. de 2016. 
FREIRE, Paulo. Pedagogia do Oprimido, $17^{\text {a }}$ Ed. Rio de Janeiro: Paz e Terra. 1987

MOREIRA, Marco Antonio. Aprendizagem Significativa: a teoria e textos complementares. São Paulo: Editora Livraria da Física, 2011.

MENDONÇA, Vivian L. Biologia: o ser humano, genética, evolução: volume 3: ensino médio. - 2ed. São Paulo: Editora AJS, 2013. p 10 - 151

NOGUEIRA, Nilbo Ribeiro. Pedagogia dos projetos: Uma jornada interdisciplinar rumo ao desenvolvimento de múltiplas inteligências - 4ed. São Paulo; Érica, 2001

PIMENTA, S. G.; LIMA, L. S. M. Estagio e docência; 7. ed - São Paulo: Cortez, 2012. 296 p.

SHIMABUKURO, Vanessa (org). Coleção Projeto Araribá: Ciências: volume 4 - 3ed. São Paulo:

Moderna, 2010.

SUART, Rita de Cássia; MARCONDES, Maria Eunice Ribeiro. A manifestação de habilidades cognitivas em atividades experimentais investigativas no ensino médio de química. Revista Ciências \& Cognição. v.14 n.1 Rio de Janeiro mar. 2009

TURRA, Clódia Maria Godoy. Planejamento de ensino e avaliação. 11 ed. Porto Alegre: Sagra, 1986.
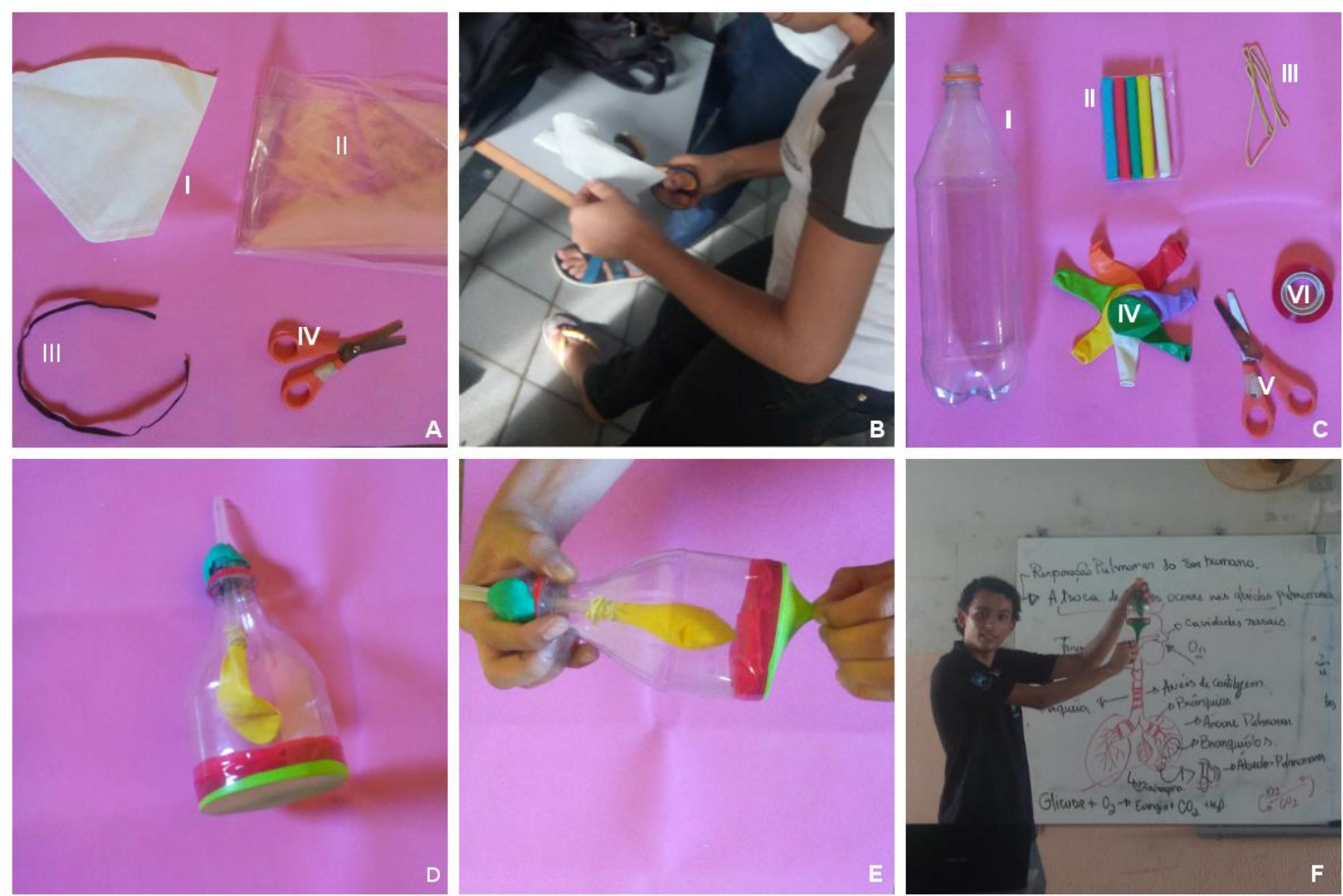

Figura 1. A. Materiais utilizados no experimento "Avaliando a qualidade do ar" - I. Papel filtro; II. Sacola isolante; III. Barbante/fio; IV. Tesoura; B. Alunos preparando material do experimento; C. Materiais e preparação do modelo para a oficina "Ventilação pulmonar" - I. Garrafa pet; II. Massa de modelar; III. Ligas de elástico; IV. Balões de festa; V. Tesoura; VI. Fita adesiva. D. Material finalizado. E. demonstração e teste de funcionalidade. F. Utilização do material durante a exposição do conteúdo (Arquivo pessoal, 2016).

RPI Revista de Pesquisa Interdisciplinar, Cajazeiras, v. 1, Ed. Especial, 437 - 443, set/dez. de 2016. 